\title{
BMJ Open Quality Improving the neonatal team handoff process in a level IV NICU: reducing interruptions and handoff duration
}

\author{
Vilmaris Quinones Cardona (D) , ${ }^{1}$ Alison LaBadie, ${ }^{1}$ David B Cooperberg, ${ }^{2}$ \\ Alan Zubrow, ${ }^{1}$ Suzanne M Touch ${ }^{1}$
}

To cite: Quinones Cardona V, LaBadie A, Cooperberg DB, et al. Improving the neonatal team handoff process in a level IV NICU: reducing interruptions and handoff duration. BMJ Open Quality 2021;10:e001014. doi:10.1136/ bmjoq-2020-001014

- Additional material is published online only. To view please visit the journal online (http://dx.doi.org/10.1136/ bmjoq-2020-001014).

Received 9 May 2020 Revised 27 November 2020 Accepted 13 January 2021
Check for updates

(C) Author(s) (or their employer(s)) 2021. Re-use permitted under CC BY-NC. No commercial re-use. See rights and permissions. Published by BMJ.

${ }^{1}$ Division of Neonatology, Department of Pediatrics, St Christopher's Hospital for Children, Drexel University College of Medicine,

Philadelphia, Pennsylvania, USA ${ }^{2}$ Division of Hospital Medicine, Department of Pediatrics, St Christopher's Hospital for Children, Drexel University College of Medicine,

Philadelphia, Pennsylvania, USA

Correspondence to Dr Vilmaris Quinones Cardona; vq23@drexel.edu

\section{ABSTRACT}

Background Neonatal intensive care unit (NICU) patients are at increased risk for handoff communication failures due to complexity and prolonged length of stay. We report a quality initiative aimed at reducing avoidable interruptions during neonatal handoffs while monitoring handoff duration and provider satisfaction.

Methods Observational time series between August 2015 and March 2018 in an academic level IV NICU. NICU I-PASS and process changes were implemented using plan-dostudy-act cycle, and statistical process control charts were used in the analysis. Unmatched preintervention and postintervention satisfaction surveys were compared using Mann-Whitney U tests.

Results There was special cause variation in the mean number of avoidable interruptions per handoff from 4 to 0.3 (92\% reduction). The mean duration of handoff was reduced $\sim 1 \mathrm{~min} /$ patient. Provider satisfaction with the quality of handoffs also improved from a mean of 3.36 to 3.75 on a $1-5$ Likert scale $(p=0.049)$.

Conclusions Standardisation of NICU handoff with NICU I-PASS and process changes led to the sustained reduction in avoidable interruptions with the added benefit of reduced handoff length and improved provider satisfaction.

\section{INTRODUCTION}

\section{Problem description}

Communication errors, including during handoffs, are one of the three most frequently identified root causes of sentinel events. ${ }^{1}$ Medical provider handoffs are complex and multifaceted events that are more than a mere passive transfer of information. ${ }^{2}$ The 2010 Accreditation Council for Graduate Medical Education (ACGME) resident duty hour restrictions led to more frequent patient handoffs. ${ }^{3}$ Subsequently, the ACGME and Agency for Healthcare Research and Quality identified improving handoffs as a priority to improve patient safety. The ACGME currently requires residency programmes to provide formal instruction and evaluation of handoffs. ${ }^{4}$

\section{Available knowledge}

Providers caring for patients in the neonatal intensive care unit (NICU) are prone to communication failures due to patients' medical complexity and prolonged length of stay. ${ }^{5}$ Furthermore, NICU handoffs typically involve an interdisciplinary team consisting of a combination of residents, fellows, neonatal nurse practitioners (NNPs), physician assistants (PAs) and/or attending physicians. These providers may have different levels of handoff education that ranges from minimal to formalised training. Yet despite the frequency of handoffs among providers, many times important information is not transmitted and these communication failures can lead to inefficient or suboptimal patient care. ${ }^{67}$

\section{Rationale}

The I-PASS Study Group developed a paediatric handoff bundle to standardise resident handoffs that included key elements for safer transfer of patient care. ${ }^{8}$ Implementation of this handoff bundle was associated with a reduction of medical errors and preventable adverse events among hospitalised children and improvements in verbal and written handoff processes. ${ }^{9}$ This bundle was designed and studied in the paediatric medical surgical unit setting but not the intensive care unit (ICU) setting. There is paucity of literature supporting NICU-specific handoff protocols, and the quality of research is lacking. ${ }^{10}$ Therefore, our team adapted I-PASS to the NICU setting, hereinafter referred to as NICU I-PASS, to improve communication and patient care.

\section{Specific aim}

We aimed to reduce the number of avoidable interruptions during shift-change handoff from 4 to 2 (50\%) by August 2016 with implementation of NICU I-PASS and handoff environment changes. Handoff duration and provider satisfaction were the balancing measures as some members of the team expressed 
concern that the use of I-PASS in the NICU environment would lengthen handoff duration.

\section{METHODS}

\section{Context}

This observational time series was conducted in an academic urban children's hospital in Philadelphia, Pennsylvania, USA and one of the original I-PASS study sites, with a 39-bed level IV NICU, between August 2015 and March 2018. The medical provider team in the NICU included residents, fellows, PAs, NNPs and attending physicians. Neonatal fellows and paediatric residents participated in a 3-hour general I-PASS training during hospital orientation. The residents used I-PASS in the general inpatient floors and rotate in the study site NICU during their second year of residency. NNPs and PAs did not participate in I-PASS training prior to this quality improvement (QI) initiative. Provider coverage included day and evening shifts and 24-hour weekend shifts. At the outset of this study, the NICU layout was 30-bed unit with four large rooms, a 10-bed step down unit, a workroom and a conference room near the unit entrance where NICU handoffs occurred. In June 2016, the NICU was relocated to a new critical care tower with 39 singlepatient rooms and multiple workrooms contiguous with patient care areas yet apart from the unit entrance.

\section{Needs assessment}

Baseline data, prior to NICU I-PASS introduction, were gathered through data collection cards from August 2015 to October 2015 to determine the duration of medical handoffs (including students, residents, PAs, NNPs and fellows), census, quantity and nature of interruptions in real time. An avoidable interruption was defined as an interruption that was neither urgent nor emergent and could have waited until handoff was complete. An example list of avoidable versus unavoidable interruptions that required an immediate response from the medical provider were provided to the fellows, NNPs and PAs who completed the data collection cards (online supplemental appendix 1). The data set included handoffs that occurred in the evening and weekends as these were identified by focus groups as high-risk encounters for interruptions. Fellows, PAs and NNPs were the only providers involved in answering questions regarding the handoff process via data collection cards. Two focus groups were held in September 2015 and October 2015 to identify areas for improvement of handoffs and also to maximise participation of fellows, NNPs and PAs. Providers identified the following handoff problems: inconsistent structure and performance, incomplete transfer of information, too many interruptions and too lengthy duration. A fishbone diagram was created illustrating contributing factors to frequently interrupted and inconsistent handoffs (figure 1A). Based on these findings, a key driver diagram was created as a framework to improve the quality of NICU medical handoffs and reduce interruptions (figure 1B). Specific interventions to address each key driver were developed and implemented sequentially via several plan-do-study-act (PDSA) cycles (table 1). A baseline survey of fellows, NNPs and PAs to assess satisfaction and perception of NICU handoffs was administered in October 2015.

\section{Intervention}

In November 2015, NICU I-PASS was introduced with the support of the I-PASS Study Group. ${ }^{11}$ Adaptation of the NICU I-PASS curriculum was performed by the study team that included two neonatologists and two neonatal fellows from the sponsoring institution and was vetted by the I-PASS Study Group. This curriculum included a NICU adapted I-PASS training session, neonatal simulation cases and a newly designed electronic handoff tool (online supplemental appendix 2). The handoff tool was changed to suit NICU-specific needs such as organising the patient summary systems based rather than problem based, including dosing weight, emergency parent contact information, consultants and laboratory schedule. The action plan was subdivided into two columns 'daytime' and 'on-call' for a more deliberate assignment of responsibility. PDSA cycle 1 included a series of training workshops that were completed in November 2015 by all NICU handoff participants. Based on a local contextual needs assessment and review of literature on error reduction, ${ }^{12}$ a protected space for handoffs and 'stop' sign on the door were simultaneously implemented to mitigate and minimise unnecessary interruptions.

Daily real-time data on duration of handoffs, patient census, quantity and nature of interruptions occurred preintervention (August 2015-October 2015) and postinterventions (November 2015-March 2018). A member of the study team reviewed data on a weekly basis. In an effort to increase consistency and completeness of data collection cards, a tally of data collection card completion was portrayed in a large monthly calendar in the medical providers' workroom starting in February 2016 highlighting days of completed and missed cards. To increase awareness of avoidable interruptions, the study team recruited a nurse champion who incorporated this discussion in the NICU Lean Daily Management Board where interruptions were presented to nursing and hospital administrative leadership biweekly (PDSA cycle 2). Interruptions were shared by a nurse champion with nurses weekly during huddle and educational sessions where examples of avoidable versus unavoidable interruptions were reviewed. Interruption data were also displayed in the NICU conference room as well as progress update sessions during fellow conference to provide feedback to nurses and attendings.

A postintervention satisfaction survey was administered in November 2016. The relocation of the NICU in June 2016 was an unintended intervention that prompted changes in process including designating a new space for handoffs that was selected away from the unit entrance but contiguous with the patient care areas. Based on the 


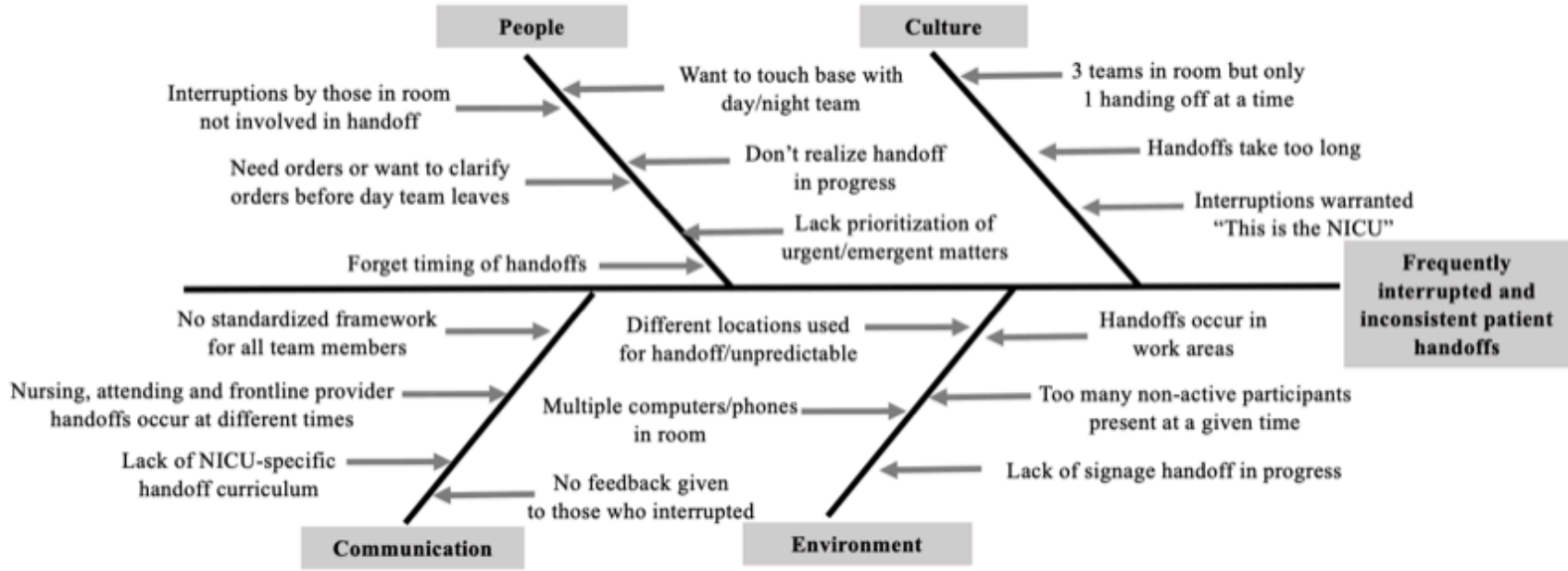

Primary Drivers

Secondary Drivers

B

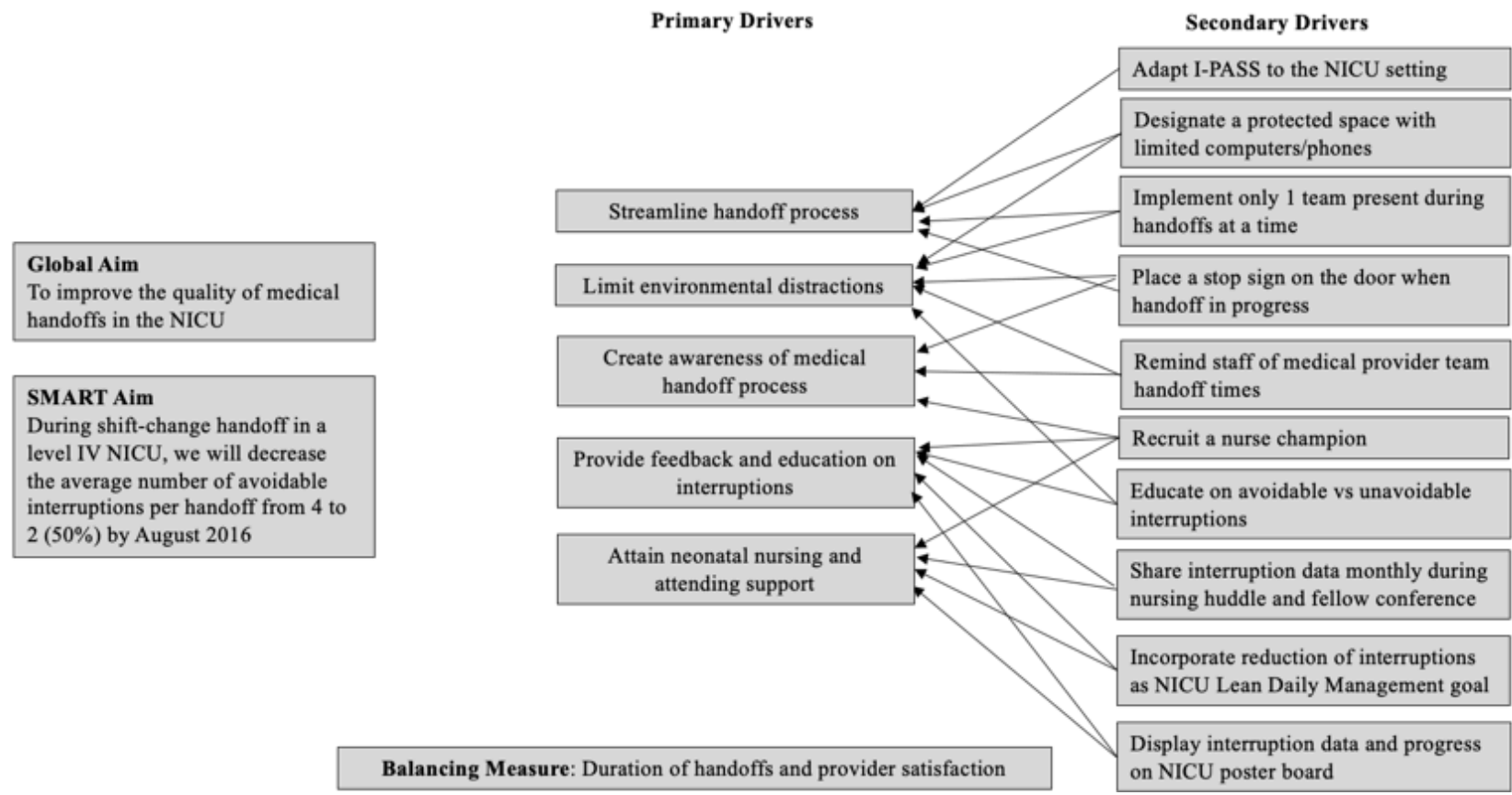

Figure 1 (A) Fishbone diagram depicting contributing factors to frequently interrupted and inconsistent patient handoffs. (B) Key driver diagram for NICU medical handoffs quality improvement initiative. NICU, neonatal intensive care unit

data, in June 2017, the handoff space was reassigned to a small consult room with five chairs and a round table, one computer and one phone, away from workrooms and patient care areas to further minimise interruptions. Only the team handing off was present to minimise distractions from other team members (PDSA cycle 3).

\section{Study of the interventions}

The interventions were trialled and refined through iterative PDSA cycles. The study team met regularly during the baseline collection phase and had meetings every 1-2 months to monitor and refine interventions.

\section{Measures}

The outcome measure was avoidable interruptions. Avoidable interruptions, as described previously, were chosen because emergencies inherently occur in the NICU and warrant handoff interruptions due to the critical nature of patients. The process measure was the per cent completion of data collection cards.

Provider satisfaction was measured prior to and 1 year following NICU I-PASS implementation. This included satisfaction with the quality of handoff as well as subjective presence of elements of handoff such as illness severity, patient summary, to-do list and contingency plans. A data collection card was created to document the duration of handoffs, patient census, quantity and nature of interruptions. Only fellows, NNPs and PAs completed the cards during/immediately after receiving handoff. Data collection completeness was defined as documentation of handoff start/stop times and number of interruptions. In an effort to increase completion of data collection cards, a tally of data collection card completion was portrayed in a large monthly calendar in the medical providers' workroom highlighting days of completed and missed cards. 


\begin{tabular}{|c|c|c|}
\hline PDSA cycle & Date & Process change \\
\hline \multirow[t]{2}{*}{ Cycle 1} & November 2015 & Education sessions for NICU fellows, NNPs and PAs on NICU I-PASS curriculum. \\
\hline & & $\begin{array}{l}\text { Education on avoidable and unavoidable interruptions given to nurses and } \\
\text { attendings. } \\
\text { New designated space for handoffs. }\end{array}$ \\
\hline \multirow[t]{2}{*}{ Cycle 2} & December 2015 & Recruitment of nurse champion. \\
\hline & & $\begin{array}{l}\text { Reducing avoidable interruptions added as a goal to Lean Daily Management QI } \\
\text { Board. } \\
\text { Reminder of medical team handoff times shared with attendings and nurses. }\end{array}$ \\
\hline \multirow[t]{2}{*}{ Cycle 3} & June 2016 & $\begin{array}{l}\text { NICU moved to a new critical care tower. } \\
\text { Data collection reminder calendar placed in the workroom. }\end{array}$ \\
\hline & June 2017 & $\begin{array}{l}\text { New smaller space for handoffs selected away from unit entrance, patient care } \\
\text { areas and workrooms with one computer. } \\
\text { Handoff limited to one team signing out at a time. }\end{array}$ \\
\hline
\end{tabular}

NICU, neonatal intensive care unit; NNPs, neonatal nurse practitioners; PAs, physician assistants; PDSA, plan-do-study-act.

Additionally, these data collection cards were strategically placed in readily available locations such as workrooms and the designated handoff room.

\section{Analysis}

Monthly average number of avoidable interruptions and duration of handoffs were displayed using statistical process control (SPC) X-bar/S charts. Mean duration of handoffs was also displayed using SPC X-bar/S charts after correcting for patient census by dividing the duration of handoff per total patients handed off per session. Monthly percentage of handoffs with zero avoidable interruptions and monthly percentage of completed data collection cards were displayed using a SPC P chart. Means, upper and lower control limits were calculated using QI Charts (Scoville Associates; 2009). Established rules for detecting special cause variation were applied. ${ }^{13}$ Preintervention and postintervention surveys were analysed using the Statistical Package for the Social Sciences V.24 software (IBM Corp, Armonk, New York, USA). Descriptive statistics were obtained and unmatched comparisons between two groups were performed using Mann-Whitney U tests. Statistical significance was defined as a $p$ value less than 0.05 .

\section{Ethical considerations}

The sponsoring institution's Institutional Review Board granted an exemption as this study was implemented to improve the quality of patient care; therefore, subject consent was not required.

\section{RESULTS}

After sequential process changes, there was special cause variation causing centreline shift in the mean number of avoidable interruptions per handoff from 4 to 0.5 by August 2016 (87\% reduction) exceeding the goal that further decreased to 0.3 (92\% reduction) by completion of the study period (figure 2). This was sustained despite movement to a new NICU. Special cause variation was achieved in the monthly rate of handoffs with zero avoidable interruptions, which increased from $11 \%$ to $60 \%$ and further to $80 \%$. During the 31-month study period, 830 days of data were collected with improvement from $73.4 \%$ to $94.2 \%$ monthly completion rate after implementing and posting the data collection reminder calendar visible in the provider workroom (online supplemental appendix 3). The duration of handoff did not increase with NICU I-PASS, rather was reduced from an average of 71 to $44 \mathrm{~min}$ (38\% reduction). After correcting for patient census, special cause variation was maintained with a reduction in the duration of handoff per patient from an average of $2 \mathrm{~min} 53 \mathrm{~s}$ to $1 \mathrm{~min} 52 \mathrm{~s}$ (reduction of $\sim 1 \mathrm{~min}$ /patient; figure 3). Criteria for special cause variation causing a centreline shift for all the measures above were established with 8 or more consecutive points above or below the mean.

A total of 14 provider surveys were completed preintervention and 12 postintervention (table 2). Presurvey and postsurveys were not matched per local IRB requirements. Participants who completed these surveys included nine fellows and five NNPs preintervention versus seven fellows and five NNPs postintervention. There was a difference 


\section{X-bar Chart}

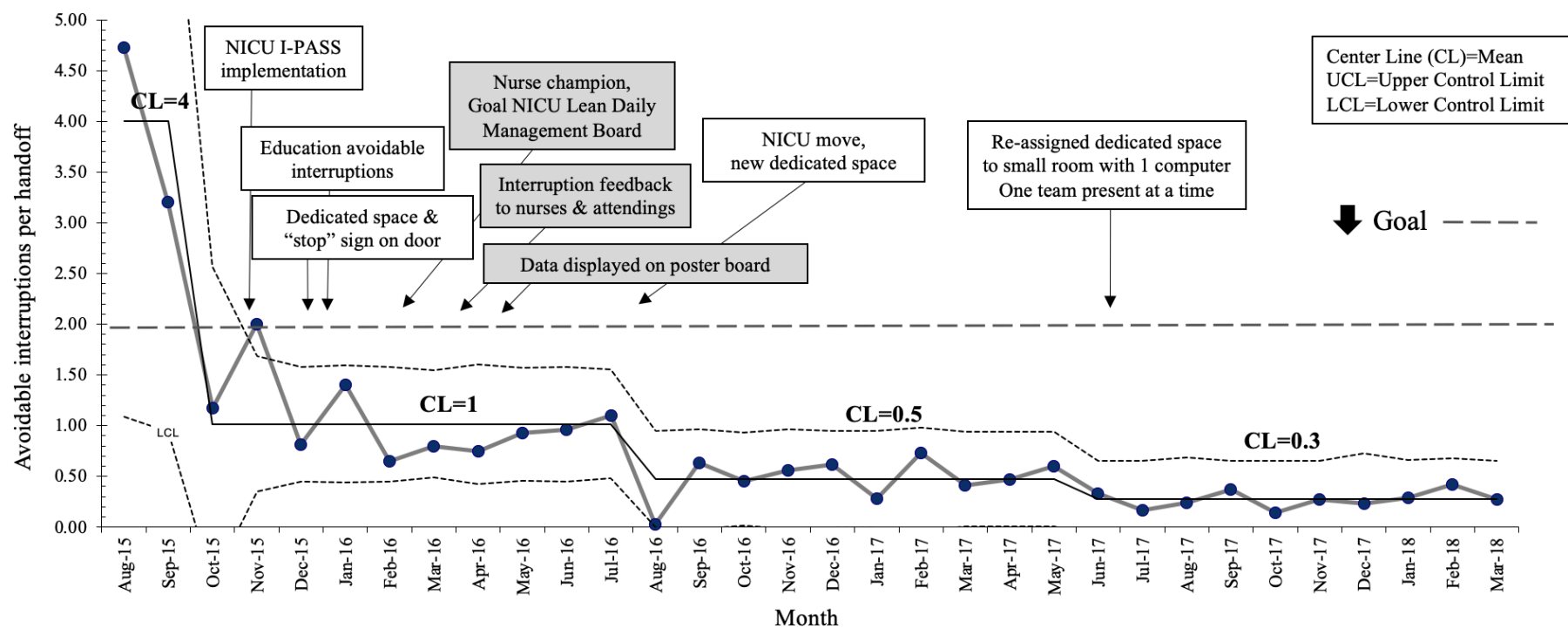

\begin{tabular}{|l|l|l|l|} 
PDSA Cycle 1 & PDSA Cycle 2 & PDSA Cycle 3
\end{tabular}

Figure 2 Average number of avoidable interruptions per handoff. NICU, neonatal intensive care unit; PDSA, plan-do-studyact.

in provider satisfaction with the quality of handoffs with means of 3.36 preintervention and 3.75 postintervention on a 1-5 Likert scale, where 1 represents 'never' and 5 represents 'always satisfied' $(\mathrm{p}=0.049)$. There was no difference between preintervention and postintervention in perceived 'important information missed' (means 3.21 vs $2.75, \mathrm{p}=0.088$ ), 'opportunity to ask questions or clarify information' (means 3.93 vs 4.33, $\mathrm{p}=0.092$ ) and 'comfort in answering patient/family questions based on information received from handoff' (means 3 vs 3.33 , $\mathrm{p}=0.078$ ).

\section{DISCUSSION}

\section{Summary}

The preintervention needs assessment identified the following handoff problems: inconsistent structure and performance, incomplete transfer of information, too many interruptions and too lengthy duration. The primary aim of reducing avoidable interruptions during evening handoffs by $50 \%$ was surpassed, with an overall reduction of $92 \%$. Likewise, the duration of handoffs was

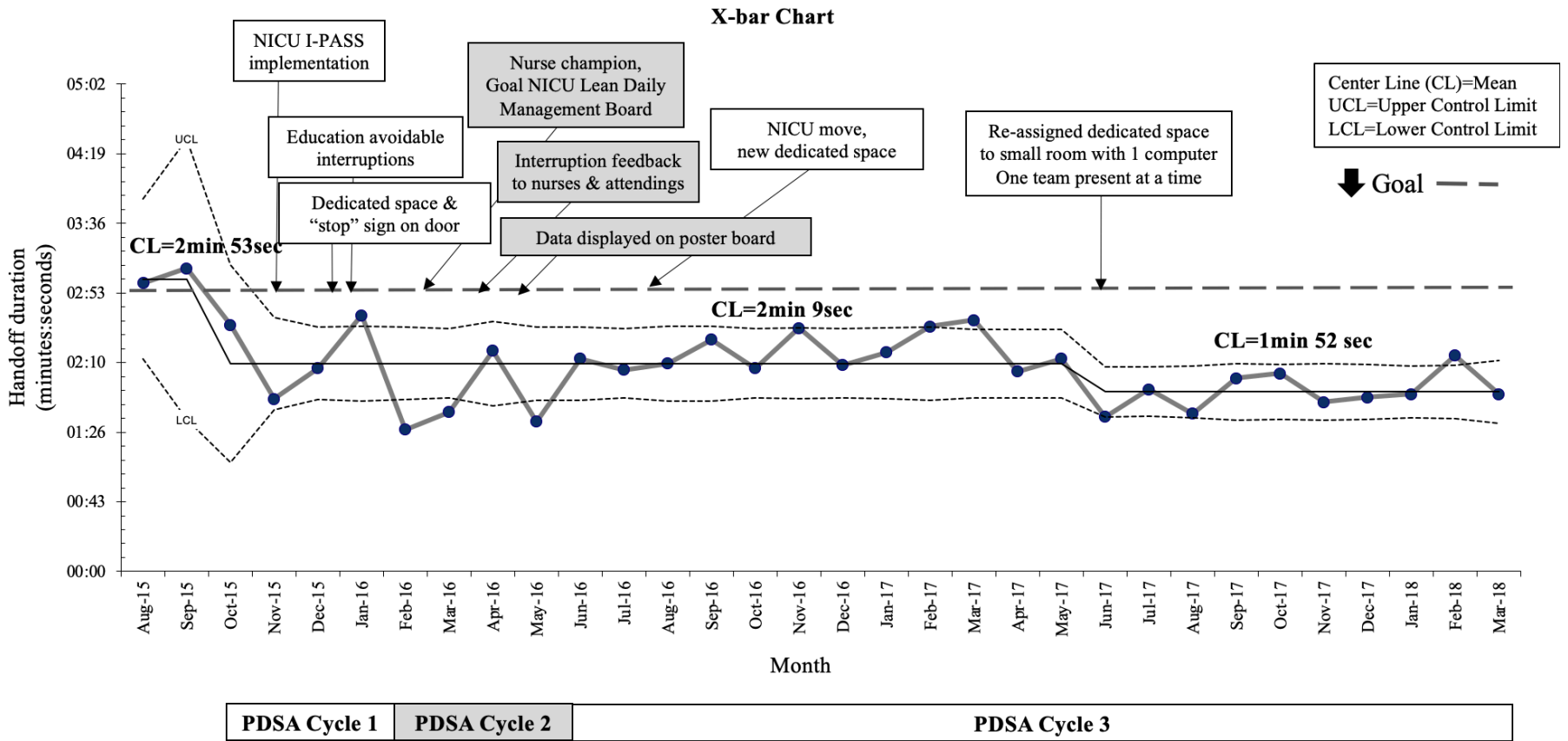

Figure 3 Average duration of handoff per patient. NICU, neonatal intensive care unit; PDSA, plan-do-study-act. 


\begin{tabular}{|c|c|c|c|}
\hline Survey question & Preintervention mean $^{+}$ & Postintervention mean ${ }^{+}$ & $P$ value \\
\hline $\begin{array}{l}\text { 'How often are you satisfied with the quality of } \\
\text { handoffs?' }\end{array}$ & 3.36 & 3.75 & $0.049^{*}$ \\
\hline $\begin{array}{l}\text { 'How often is the severity of illness adequately } \\
\text { conveyed?' }\end{array}$ & 3.86 & 3.75 & 0.618 \\
\hline $\begin{array}{l}\text { 'How often is important information directly impacting } \\
\text { care missed?' }\end{array}$ & 3.21 & 2.75 & 0.088 \\
\hline 'How often do you receive clear contingency plans?' & 3.07 & 3.5 & 0.125 \\
\hline $\begin{array}{l}\text { 'How often do you receive clear "to do" list when } \\
\text { applicable for patients?' }\end{array}$ & 3.36 & 3.75 & 0.259 \\
\hline $\begin{array}{l}\text { 'How often do you get an opportunity to ask questions } \\
\text { or clarify information?' }\end{array}$ & 3.93 & 4.33 & 0.092 \\
\hline $\begin{array}{l}\text { 'How often do you summarize relevant data and re-state } \\
\text { to do items for applicable patients?' }\end{array}$ & 2.79 & 3 & 0.643 \\
\hline $\begin{array}{l}\text { 'How often do you feel confident answering patient/ } \\
\text { family questions based on information received from } \\
\text { handoff?' }\end{array}$ & 2.79 & 3.42 & 0.078 \\
\hline $\begin{array}{l}\text { 'How often do you feel confident answering nursing/ } \\
\text { attending/consultant questions based on information } \\
\text { received from handoff?' }\end{array}$ & 3.07 & 3.5 & 0.119 \\
\hline $\begin{array}{l}\text { 'How often is escalation of care anticipated during } \\
\text { handoff?' }\end{array}$ & 3 & 3.33 & 0.209 \\
\hline 'How often is electronic handoff document accurate?' & 2.88 & 3.33 & 0.105 \\
\hline
\end{tabular}

'Likert scale 1-5: 1='never', 2='rarely', 3='sometimes', 4='often' and 5='always'.

*Statistically significant $p$ value $<0.05$.

reduced by an average of $1 \mathrm{~min} /$ patient, while provider satisfaction improved.

\section{Interpretation}

High-intensity and high-stress environments, such as the ICU, increase the susceptibility of patients to medical errors due to their severity of illness. ${ }^{14}$ The NICU is an example of such environment where handoffs are a common source of medical communication errors especially among sick infants. ${ }^{5}$ Handoff-related care failures can be reduced with standardisation of handoffs. ${ }^{15}$ For these reasons, the adaptation and implementation of our NICU I-PASS curriculum and handoff format served as major interventions in this initiative to provide a uniform handoff framework for trainees, NNPs and PAs.

The reduction of avoidable interruptions correlated with a reduction in the duration of handoff that persisted after correcting for patient census. This was demonstrated immediately after implementation of NICU I-PASS and modifications to the handoff environment by designating a private handoff space, placing a 'stop' sign on the door and obtaining stakeholder engagement from unit secretaries, nurses and attending physicians prioritising the importance of handoff. Reduction in avoidable interruptions may have minimised unnecessary distractions, which are very common during handoffs and have been shown to increase handoff length. ${ }^{16}$ Furthermore, this project led to a culture change where attendings and nurses thoughtfully minimised avoidable interruptions that was a critical point in our initiative. This was evidenced by observing minimal variability in this outcome measure despite the move to a new NICU. In addition, we speculate that using a standardised handoff method with a concise patient summary may have also contributed to a more efficient and focused handoff.

This initiative altered the culture and environment surrounding NICU handoffs, reduced avoidable interruptions and provided a standardised handoff process for all medical providers including trainees, NNPs and PAs. Interruptions can lead to communication failures that may be detrimental to patient safety in such a vulnerable population. These QI interventions were low cost and labour intensive but of high impact in such an error-prone process. Provided with invested leadership, educators and staff, this QI initiative can be replicated in other NICUs. Given provider satisfaction including fellows, NNPs and PAs in the quality of handoffs, these interventions can be applied to NICUs with varied models of medical providers who participate in handoffs. Relocating to a new NICU was a unique and unplanned event during this initiative that provided an additional challenge but does not limit generalisability. Moreover, we learnt that a small room with only one 
computer for emergent orders, a 'stop' sign on the door and only those participating in handoffs present at a given time further reduced avoidable interruptions. These specifications defined the ideal space for our NICU handoffs.

The success of this project relied heavily on the engagement of all NICU medical providers and support staff, which was fundamental to this project's implementation and sustainability. Another major key to success was the endorsement of the I-PASS Study Group to adapt their previously validated paediatric handoff bundle to the NICU setting. ${ }^{8}$

\section{Limitations}

There were several limitations to this study. First, it relied exclusively on subjective reports from fellows, NNPs and PAs. This potential confounder was minimised by defining our outcome measure and limiting the group of reporters to fellows, NNPs and PAs. The NNP and PA teams remained constant throughout the study; however, due to the duration of fellowship training, some fellows graduated while others commenced. Recall bias was another possible limitation if the data collection cards were not completed as intended, although reporters were encouraged to complete data collection cards in real-time during fellow meetings and with a completion reminder calendar to mitigate this possibility. A potential limitation to external generalisability was that trainees had received training with I-PASS during their orientation, some trainees had prior experience using I-PASS handoff in the general inpatient units and given this exposure they may have been more open to the use of NICU I-PASS. However, it is important to note that our NNPs and PAs had neither I-PASS training nor experience prior to this initiative, and this was not a barrier for success as all participants were uniformly trained with the NICU I-PASS curriculum. Finally, the baseline period for this study was deliberately shortened as the data confirmed the magnitude of the problem correlated with anecdotal reports of frequent interruptions. Therefore, the study team decided to proceed with the intervention phase rather than delay to collect more data.

\section{CONCLUSIONS}

This QI initiative encompassing environment changes surrounding NICU handoffs and implementing a uniform handoff process and content with the use of NICU I-PASS led to the sustained reduction in avoidable interruptions with the added benefits of reduced handoff duration and improved provider satisfaction. The key drivers for success were engagement of trainees, NNPs and PAs, as well as shifting to protected handoffs, in a designated location, that were seldom interrupted. Next steps include addressing communication errors, assessing the generalisability of this study in other level NICUs with varied composition of medical providers involved in handoffs as well as NICU I-PASS curriculum validation.
Future directions include dissemination of this innovative handoff QI initiative to other institutions and to serve as a model for the adaptation of I-PASS to other subspecialties and ICUs.

Acknowledgements We would like to thank the fellows, neonatal nurse practitioners and physician assistants in the neonatal intensive care unit at St Christopher's Hospital for Children for their data collection and buy-in. We would like to thank Jessica May-Rabbach, MD, for her help in the NICU I-PASS curriculum training as well as the paediatric residents, attendings, nursing staff and unit secretaries at St Christopher's Hospital for Children NICU for their contributions. We would also like to thank the I-PASS Study Group for their support and endorsement.

Contributors All authors are responsible for reported research and have participated in the concept and design, analysis and interpretation of data, drafting or revising of the manuscript. All authors have approved the manuscript as submitted.

Funding The authors have not declared a specific grant for this research from any funding agency in the public, commercial or not-for-profit sectors.

Competing interests None declared.

Patient consent for publication Not required.

Provenance and peer review Not commissioned; externally peer reviewed.

Data availability statement All data relevant to the study are included in the article.

Supplemental material This content has been supplied by the author(s). It has not been vetted by BMJ Publishing Group Limited (BMJ) and may not have been peer-reviewed. Any opinions or recommendations discussed are solely those of the author(s) and are not endorsed by BMJ. BMJ disclaims all liability and responsibility arising from any reliance placed on the content. Where the content includes any translated material, BMJ does not warrant the accuracy and reliability of the translations (including but not limited to local regulations, clinical guidelines, terminology, drug names and drug dosages), and is not responsible for any error and/or omissions arising from translation and adaptation or otherwise.

Open access This is an open access article distributed in accordance with the Creative Commons Attribution Non Commercial (CC BY-NC 4.0) license, which permits others to distribute, remix, adapt, build upon this work non-commercially, and license their derivative works on different terms, provided the original work is properly cited, appropriate credit is given, any changes made indicated, and the use is non-commercial. See: http://creativecommons.org/licenses/by-nc/4.0/.

ORCID iD

Vilmaris Quinones Cardona http://orcid.org/0000-0001-5384-2429

\section{REFERENCES}

1 The Joint Commission. Sentinel event statistics data: root causes by event type. available. Available: http://www.jointcommission.org/ sentinel_event_statistics [Accessed 27 May 2016].

2 Wohlauer MV, Arora VM, Horwitz LI, et al. The patient handoff: a comprehensive curricular blueprint for resident education to improve continuity of care. Acad Med 2012;87:414-8.

3 Nasca TJ, Day SH, Amis ES, et al. The new recommendations on duty hours from the ACGME Task force. N Engl J Med 2010;363:e3.

4 Acgme common program requirements effective, 2013. Available: http://www.acgme.org/What-We-Do/Accreditation/CommonProgram-Requirements [Accessed 27 May 2016].

5 Derienzo C, Lenfestey R, Horvath M, et al. Neonatal intensive care unit handoffs: a pilot study on core elements and epidemiology of errors. J Perinatol 2014;34:149-52.

6 Borowitz SM, Waggoner-Fountain LA, Bass EJ, et al. Adequacy of information transferred at resident sign-out (in-hospital handover of care): a prospective survey. Qual Saf Health Care 2008;17:6-10.

7 Arora V, Johnson J, Lovinger D, et al. Communication failures in patient sign-out and suggestions for improvement: a critical incident analysis. Qual Saf Health Care 2005;14:401-7.

8 I-PASS Study Group,. Handoff curriculum materials. available. Available: http://ipassstudygroup.com [Accessed 20 Nov 2016].

9 Starmer AJ, Sectish TC, Simon DW, et al. Rates of medical errors and preventable adverse events among hospitalized children following implementation of a resident handoff bundle. JAMA 2013;310:2262-70. 
10 Gephart SM. The art of effective handoffs: what is the evidence? Adv Neonatal Care 2012;12:37-9.

11 Sectish TC, Starmer AJ, Landrigan CP, et al. Establishing a multisite education and research project requires leadership, expertise, collaboration, and an important aim. Pediatrics 2010;126:619-22.

12 Federwisch M, Ramos H, Adams Shonte' C. The sterile cockpit: an effective approach to reducing medication errors? Am J Nurs 2014;114:47-55.

13 Provost LP, Murray S. The health care data guide: learning from data improvement. San Francisco, CA, USA: Jossey-Bass Publishers, 2011: 107-36.
14 Donchin Y, Gopher D, Olin M, et al. A look into the nature and causes of human errors in the intensive care unit. 1995. Qual Saf Health Care 2003;12:143-7. ;discussion147-8.

15 Bigham MT, Logsdon TR, Manicone PE, et al. Decreasing Handoff-Related Care Failures in Children's Hospitals. Pediatrics 2014;134:e572-9.

16 Anderson CE, Nicksa GA, Stewart L. Distractions during resident handoffs: incidence, sources, and influence on handoff quality and effectiveness. JAMA Surg 2015;150:396-401. 